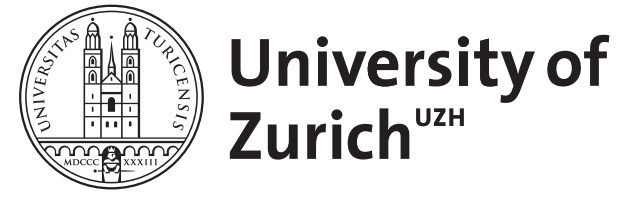

\title{
Transfusion strategy in multiple trauma patients
}

\author{
Theusinger, Oliver M ; Stein, Philipp ; Spahn, Donat R
}

\begin{abstract}
PURPOSE OF REVIEW To point out the tolerance of anemia, the possible use of alternatives to allogeneic blood products as well as the pathophysiological effects of transfusions in the context of multiple trauma patients. RECENT FINDINGS Restrictive transfusion triggers are beneficial for patient outcome in trauma.The actual European Trauma Treatment Guidelines suggest the use of point-of-care devices, the use of transfusion algorithms and factor concentrates to control coagulopathy. The use of high ratios of plasma to red blood cells to improve survival has been shown to suffer from a time-dependent survival bias. In massive bleeding, factor-based treatment of coagulopathy is feasible and preferable to plasma transfusion, if available. In nonmassive bleeding, allogeneic transfusion of blood products increases the appearance of serious adverse events and mortality and should be avoided unless clearly indicated. SUMMARY Transfusion in trauma has to be an individual decision for a specific patient, not for a specific laboratory value. Transfusion management must aim at reducing or even avoiding the use of allogeneic blood products. This may lead to a new gold standard with cost reduction and amelioration of outcome of major trauma patients.
\end{abstract}

DOI: https://doi.org/10.1097/MCC.0000000000000152

Posted at the Zurich Open Repository and Archive, University of Zurich

ZORA URL: https://doi.org/10.5167/uzh-101111

Journal Article

Published Version

Originally published at:

Theusinger, Oliver M; Stein, Philipp; Spahn, Donat R (2014). Transfusion strategy in multiple trauma patients. Current Opinion in Critical Care, 20(6):646-655.

DOI: https://doi.org/10.1097/MCC.0000000000000152 


\title{
Transfusion strategy in multiple trauma patients
}

\author{
Oliver M. Theusinger, Philipp Stein, and Donat R. Spahn
}

\begin{abstract}
Purpose of review
To point out the tolerance of anemia, the possible use of alternatives to allogeneic blood products as well as the pathophysiological effects of transfusions in the context of multiple trauma patients.

\section{Recent findings}

Restrictive transfusion triggers are beneficial for patient outcome in trauma.

The actual European Trauma Treatment Guidelines suggest the use of point-of-care devices, the use of transfusion algorithms and factor concentrates to control coagulopathy. The use of high ratios of plasma to red blood cells to improve survival has been shown to suffer from a time-dependent survival bias. In massive bleeding, factor-based treatment of coagulopathy is feasible and preferable to plasma transfusion, if available. In nonmassive bleeding, allogeneic transfusion of blood products increases the appearance of serious adverse events and mortality and should be avoided unless clearly indicated.
\end{abstract}

\section{Summary \\ Transfusion in trauma has to be an individual decision for a specific patient, not for a specific laboratory value. Transfusion management must aim at reducing or even avoiding the use of allogeneic blood products. This may lead to a new gold standard with cost reduction and amelioration of outcome of major trauma patients.}

\section{Keywords}

allogeneic blood products, assessment of anemia, pathophysiology of transfusions, transfusion triggers, trauma

\section{INTRODUCTION}

Mortality related to trauma may be up to $40 \%$ in the civilian sector $\left[1^{\boldsymbol{*}}, 2,3\right]$. Of those $40 \%$, one quarter of the deaths are related to coagulopathy and uncontrolled blood loss that may be preventable $\left[4^{-"}, 5\right]$. For this reason, treatment of coagulopathy and hemostatic control are key to reduce mortality due to exsanguination, to save blood products and to improve outcome [1"',6-11].

Using restrictive transfusion triggers and patientspecific physiological reserve of anemia are the two aspects that can also be applied in multiple trauma patients to reduce the use of blood products [12",13",14"',15,16"'].

Point-of-care (POC) devices, such as rotational thromboelastometry (ROTEM, TEM Innovations $\mathrm{GmbH}$, Munich, Germany) or thromboelastography (TEG, Haemoscope Corporation, Niles, Illinois, USA) are becoming more popular to treat bleeding in trauma and are highly recommended to guide hemostatic therapy during coagulopathy $\left[1^{-\prime}, 17,18\right]$.

The purpose of this review is to enlighten patient tolerance to anemia, the use of transfusion algorithms and alternatives to allogeneic blood products, the outcome of transfused patients, complications and pathophysiological effects of blood products as well as transfusion triggers and thresholds to use blood products in a restrictive manner.

\section{PATHOPHYSIOLOGICAL EFFECTS OF TRANSFUSION}

Although blood transfusions are considered to be well tolerated in first world countries with regard to the direct transmission of infectious agents, there are still some serious adverse events that need to be mentioned. Although their frequency is low, hemolytic and delayed hemolytic reactions are severe adverse events [19]. They may be due to the transfusion of $\mathrm{ABO}$ incompatible blood product. Delayed

Institute of Anesthesiology, University Hospital of Zurich, University of Zurich, Zurich, Switzerland

Correspondence to Oliver M. Theusinger, MD, PrivatDozent, Institute of Anesthesiology, University Hospital of Zurich and University of Zurich, Rämistrasse 100, CH-8091 Zurich, Switzerland. Tel: +41 4425527 10; fax: +41 4425544 09; e-mail: oliver.theusinger@usz.ch

Curr Opin Crit Care 2014, 20:646-655

DOI:10.1097/MCC.0000000000000152 


\section{KEY POINTS}

- Also, in trauma, restrictive transfusion triggers are beneficial for patient outcome.

- Goal-directed transfusion algorithms and the use of POC devices in trauma reduce the need of allogeneic blood products.

- There is no clear evidence for high FFP: RBC ratios as this concept suffers from a time-dependent survival bias in patients receiving high FFP: RBC ratios.

hemolytic reactions occur in patients who have developed antibodies from previous (ABO compatible) transfusions or pregnancy. These antibodies in question sometimes present in low concentrations and are too weak to be detected by standard procedures at the time of antibody screening before the intended transfusion. Subsequent transfusion with red blood cells (RBCs) having the corresponding antigen results in an anamnestic antibody response and consecutive hemolysis of transfused RBCs. Febrile reactions (a rise of $1.0^{\circ} \mathrm{C}$ from baseline) due to cytokines and antibodies to leukocyte antigens reacting with leukocytes or leukocyte fragments are common with a frequency of about $10 \%$ [19]. Foreign plasma proteins are able to cause allergic reactions causing urticaria and may be associated with laryngeal edema and bronchospasm; their frequency is about $1 \%$. Anaphylactic reactions are rare and may be due to an anti-immunoglobulin A reaction, leading to cardiovascular instability, dyspnea, stridor, shock and possible cardiac arrest. Transfusion-related acute lung injury (TRALI) is underrecognized, and thus its frequency is rare $\left[20^{*}\right]$. The pathomechanism is supposed to be linked to the presence of antibodies in the donor plasma, which react with the recipient's leukocyte antigens or induce the production of inflammatory mediators resulting in a noncardiogenic pulmonary edema with a $10 \%$ fatality $\left[21,22^{\circ}\right]$. Bacterial contamination occurs when a small number of bacteria enter a blood component during collection or processing. During storage, bacteria may proliferate, resulting in a large number of organisms and endotoxins being given with the transfusion. This complication is rare in first world countries but leads to major complications including fatalities [23"].

In addition to the above-mentioned distinctive side-effects, RBC transfusions in trauma patients increase the risk of multiorgan failure, infections, renal dysfunction, length of stay (LOS) and mortality $[24,25]$.

Trauma patients are at greater risk for massive transfusion. In addition, longer storage time of RBCs
[26-28] leads to even longer LOS [29,30], additional occurrence of deep vein thrombosis [31] and even higher mortality [26,30-33] with a possible dose effect regarding older blood products $[27,31,33]$.

\section{ASSESSMENT OF ANEMIA IN TRAUMA}

The initial hemoglobin or hematocrit measurement is not a precise measure of the actual blood loss of a trauma victim, particularly after a limited initial fluid therapy. Therefore, a near normal hematocrit value in the emergency department does not rule out significant blood loss (low sensitivity) [34]. But, a primarily low hematocrit has a high specificity in identifying major injury and blood loss requiring operative intervention [34,35]. Moreover, a low hematocrit is associated with higher injury severity scores, hypotension and acidosis [36]. Preexisting anemia or severe hemodilution cannot be ruled out as other reasons for a low hematocrit, but a drop in the hematocrit value over time (serial measurement) is sensitive and specific for bleeding, even in the context of fluid resuscitation [37].

In 2002, Kinoshita et al. [38] were the first to describe an apparatus to measure hemoglobin concentrations noninvasively using three different wavelengths. The development of multiwavelength pulse oximeters showed promising results and a relatively acceptable accuracy in perioperative patients when peripheral perfusion, indexed as signal quality by the machine, was good (in 70\% of cases) [39]. However, for trauma patients, this method is inadequate as shock, hypothermia and vasoconstriction influence the results $\left[40,41^{\prime}\right]$. In a study comprising 525 trauma patients, detection of a hemoglobin value was impossible only in $34 \%$ of the readouts [42].

Although noninvasive hemoglobin measurement shows promising results in patients with an adequate peripheral perfusion, it is not yet useful in the setting of trauma and hemorrhagic shock to guide transfusion decision making.

\section{TRANSFUSION TRIGGERS AND THRESHOLDS (THE EMPIRICAL APPROACH)}

Blood transfusion historically is thought to save the life of bleeding patients, but no high evidence data are available to date to support this axiom [43].

In the perioperative setting, not referring specifically to trauma victims, anemic patients have a significantly higher perioperative 30-day mortality after major noncardiac surgery, compared to controls with normal hemoglobin levels $[44,45]$. 
However, allogeneic blood transfusion is not the 'cure' for the anemic patient. Specific risks, such as (viral) infection, TRALI, transfusion-related circulatory overload and immunomodulation, account for the transfusion-associated worsened outcome $[46,47]$.

Formerly accepted hemoglobin transfusion triggers of about $100 \mathrm{~g} / \mathrm{l}$ were abandoned [48].

A Cochrane review concerning transfusion triggers states that blood transfusion probably can be withheld to hemoglobin levels of as low as $70 \mathrm{~g} / \mathrm{l}$. The threshold for patients with coronary artery disease remains to be exactly determined but is likely at or below $80 \mathrm{~g} / \mathrm{l}$. Further research is needed to evaluate the role of even lower hemoglobin levels [9]. A randomized controlled multicenter study showed a lower mortality, fewer complications and a shorter length of hospital stay in patients with acute upper gastrointestinal bleeding when transfused restrictively $(\mathrm{Hb}<70 \mathrm{~g} / \mathrm{l})$ as compared with a more liberal transfusion regimen $(\mathrm{Hb}$ $<90 \mathrm{~g} / \mathrm{l}$ ) [49"']. In hip fracture surgery patients with a history of, or risk factors for, cardiovascular disease, liberal transfusion strategy (threshold $100 \mathrm{~g} / \mathrm{l}$ ) did not reduce rates of death on 60-day follow-up or reduce in-hospital morbidity in elderly patients [50].

In 203 trauma patients, analyzed as a subgroup of the prospective randomized controlled 'transfusion requirements in critical care' trial [51], a restrictive transfusion trigger $(<70 \mathrm{~g} / \mathrm{l})$ to maintain hemoglobin between 70 and $90 \mathrm{~g} / \mathrm{l}$ was not inferior to a liberal $(>100 \mathrm{~g} / \mathrm{l})$ regimen with hemoglobin concentrations between 100 and $120 \mathrm{~g} / \mathrm{l}$. Patients in the restrictive group received significantly fewer allogeneic RBC transfusions. Reported 30-day allcause mortality, rate of multiorgan dysfunction, LOS in the hospital and in the ICU were comparable and not significantly different between the two groups [51].

In patients with traumatic brain injury (TBI), RBC transfusion increased local brain tissue oxygen partial pressure in $74 \%$ of the patients [52]. However, this effect was not seen with 'old' blood stored more than 19 days [53]. Despite increased oxygen partial pressure, no positive effect on cerebral metabolism was seen [54]. More days with a hematocrit below 30\% were associated with improved neurologic outcomes in a retrospective analysis of 169 patients [55]. Transfusion, but not anemia, significantly led to higher mortality and more complications among 1150 TBI patients [56]. Increasing the hematocrit above $28 \%$ in the initial operation phase following severe TBI was not associated with an increased or decreased morbidity or mortality [57]. Initial anemia $(\mathrm{Hb}<100 \mathrm{~g} / \mathrm{l})$ in the emergency department following TBI was not a mortality risk factor [58].

The current knowledge gives no compelling evidence to treat patients with severe TBI differently in contrast to other critically ill patients concerning RBC transfusion [1""].

Clinical indicators such as injury severity score above 25 , the need for procedural bleeding control [59"] and multiple scoring systems consisting of international normalized ratio (INR), mechanism of injury, positive results for focused assessment with sonography for trauma, blood pressure, initial hemoglobin and heart rate can help identify trauma patients at risk for massive transfusion, but also patients highly unlikely to need a massive transfusion $\left[60^{-}, 61\right]$. These variables and scores may be used as an adjunct to guide resuscitation, but they do not reflect the specific needs of an individual trauma victim.

Emphasis must be put on the fact that transfusion has to be an individual decision for a specific patient at a specific moment in time, not for a specific hemoglobin value, and RBC transfusion must be avoided whenever possible.

\section{ACUTE ANEMIA, HEMODILUTION AND ANEMIA TOLERANCE (THE INDIVIDUAL PHYSIOLOGICAL APPROACH)}

Only $0.3 \mathrm{ml}$ of oxygen is dissolved physically in $100 \mathrm{ml}$ of blood at room air breathing (FiO2 0.21 and atmospheric pressure $1013 \mathrm{mbar}$ ), but it can play a vital role in severe acute anemia states. With a FiO2 of 1.0 and a hemoglobin value of $10 \mathrm{~g} / \mathrm{l}$, the physically dissolved amount of oxygen equals the amount of oxygen bound to hemoglobin [62]. Survival of transient acute anemia (hemoglobin $7 \mathrm{~g} / \mathrm{l}$ ) was reported [63]. Even without allogeneic blood transfusion, a nadir hemoglobin of $14 \mathrm{~g} / \mathrm{l}$ was survived by a patient refusing blood products [64].

Cellular and circulatory physiological compensatory mechanisms facilitate vital oxygen delivery to the tissues (DO2) during anemia [65"]. DO2 is the product of cardiac output and arterial oxygen content of the blood. The body's demand for oxygen is five-fold exceeded by DO2 in physiological conditions. Moreover, a rise in cardiac output and an increase in $\mathrm{O}_{2}$ extraction can compensate for a decline in the oxygen content of the blood in states of acute anemia [66].

A critical hemoglobin value $[\mathrm{Hb}(\mathrm{crit})]$ is reached when whole body oxygen consumption (VO2) starts to decline because of insufficient DO2 (=global body hypoxia). In an animal model, all of the study pigs consecutively died within $3 \mathrm{~h}$ after reaching the 
$\mathrm{Hb}$ (crit) with a FiO2 of 0.21 [67]. Increasing the FiO2 leads to more physically dissolved oxygen, resulting in a lower $\mathrm{Hb}$ (crit) and a higher level of possible hemodilution [68"].

In addition, Lauscher et al. [69"'] demonstrated that there are organ-specific thresholds of anemic hypoxia in anesthetized pigs. Kidney and skeletal muscle showed tissue hypoxia before reaching $\mathrm{Hb}$ (crit) and significantly earlier than cardiac ventricle and brain. On the contrary, the liver showed even fewer cellular signs of hypoxia at a hemoglobin level of $40 \mathrm{~g} / \mathrm{l} \mathrm{compared} \mathrm{with} \mathrm{the} \mathrm{control} \mathrm{group} \mathrm{(nor-}$ mal hemoglobin values) [69"']. The impact of this animal model data is unclear for the time being. Further investigations need to be performed to elucidate the clinical relevance in the human body. Moreover, current transfusion thresholds $(70 \mathrm{~g} / \mathrm{l})$ are high above the critical individual organ margin described in the animal study.

Other clinically susceptible factors to increase anemia tolerance are deep neuromuscular blockade [70], hypothermia, by reducing (cerebral) oxygen consumption by $6 \%$ per degree Celsius [71] and administration of norepinephrine to overcome arterial hypotension during hemodilution [72].

This growing knowledge may lead to a better understanding of the role of transfusion in the context of severe traumatic bleeding. Measures to increase anemia tolerance, further insights into organ-specific oxygen demand and assessment of organ ischemia thresholds may reveal new physiologic triggers to guide red cell transfusion therapy in the future.

\section{ALTERNATIVES TO ALLOGENEIC BLOOD PRODUCTS}

Actual studies clearly show that a high amount of RBCs, fresh frozen plasmas (FFPs) and platelets can be reduced without additional risks for patients by using transfusion algorithms in trauma on the basis of coagulation factor concentrates $[73,74]$. Data from four European countries (United Kingdom, Germany, Italy and Switzerland) were used to calculate blood substitution and costs of blood products needed. The results showed that these products account for approximately one third of all costs associated with trauma care [75]. The reduction of septic complications and organ failure tends to reduce days on ventilator, whilst on ICU and shorten overall in-hospital LOS which clearly contribute to cost reduction in trauma care without increasing the risk of patients [76].

The use of POC devices as well as goaldirected algorithms is getting essential (Fig. 1)
[77"']. Because of their use, coagulopathy in trauma can be treated early and effectively and blood loss and the use of blood products can be reduced $\left[1^{" *}, 78^{-"}, 79^{\prime \prime}\right]$.

Thromboelastometry (ROTEM) measures and graphically displays the viscoelasticity of the developing blood clot. The first usable results are provided within 5-10 min, whereas the classical laboratory results may take from 30 to $90 \mathrm{~min}$ and thereby delay effective therapy for patients [77"']. Details on the ROTEM method and technology are to be found in the literature [80]. Another device to be used is the thromboelastography (TEG, Haemoscope Corporation, Niles, Illinois, USA) working similarly to the ROTEM, details are described in the literature [81]. The use of POC devices is acutely clearly recommended by the European Trauma Guidelines [1"'].

The use of FFP leads to adverse effects that are similar to those of RBCs (increased mortality, multiple organ failure, infections, lung injury, immunomodulation) [82"]. The use of FFP is getting more and more questionable as concentrations of factors are variable and large volumes are necessary to achieve an effect. Actually, the use of fibrinogen concentrates is favorable compared with FFPs [83]. According to the European Trauma Guidelines, the use of FFP or fibrinogen is indicated in patients with massive transfusions. A ratio of $1: 2$ (FFP:RBC) is suggested if FFP is being used. However, in nonmassive bleeding, plasma transfusion should be avoided [1"']. Fibrinogen has been shown to be the coagulation factor which drops critically first during bleeding; for this reason, its concentration needs to be monitored closely $\left[1^{\prime}, 73,84\right]$. The actual recommended fibrinogen target levels of $1.5-2.0 \mathrm{~g} / \mathrm{l}$ have been defined by the European Trauma Treatment Guidelines [1"']. As the concentration of fibrinogen in FFP does not exceed $2 \mathrm{~g} / \mathrm{l}$, the use of fibrinogen concentrates has the advantage of reaching fibrinogen levels above $2.0 \mathrm{~g} / \mathrm{l}$ without volume overload [85]. The second coagulation factor to be monitored closely is factor XIII which, in combination with fibrinogen, is essential for a stable clot; its level should be maintained above $60 \%$ by administration of factor concentrate in case of active bleeding [86-89]. In addition to those single-factor concentrates, prothrombin complex concentrates may be taken into consideration [73,89-93]. There are different types of prothrombin complex concentrates regarding factors contained (three vs. four), their relative composition and their thrombotic potential. Their use in trauma is recommended since 2013, but only under strict surveillance by rotational thromboelastometry and in the context of algorithms, which suggest small and repeated 


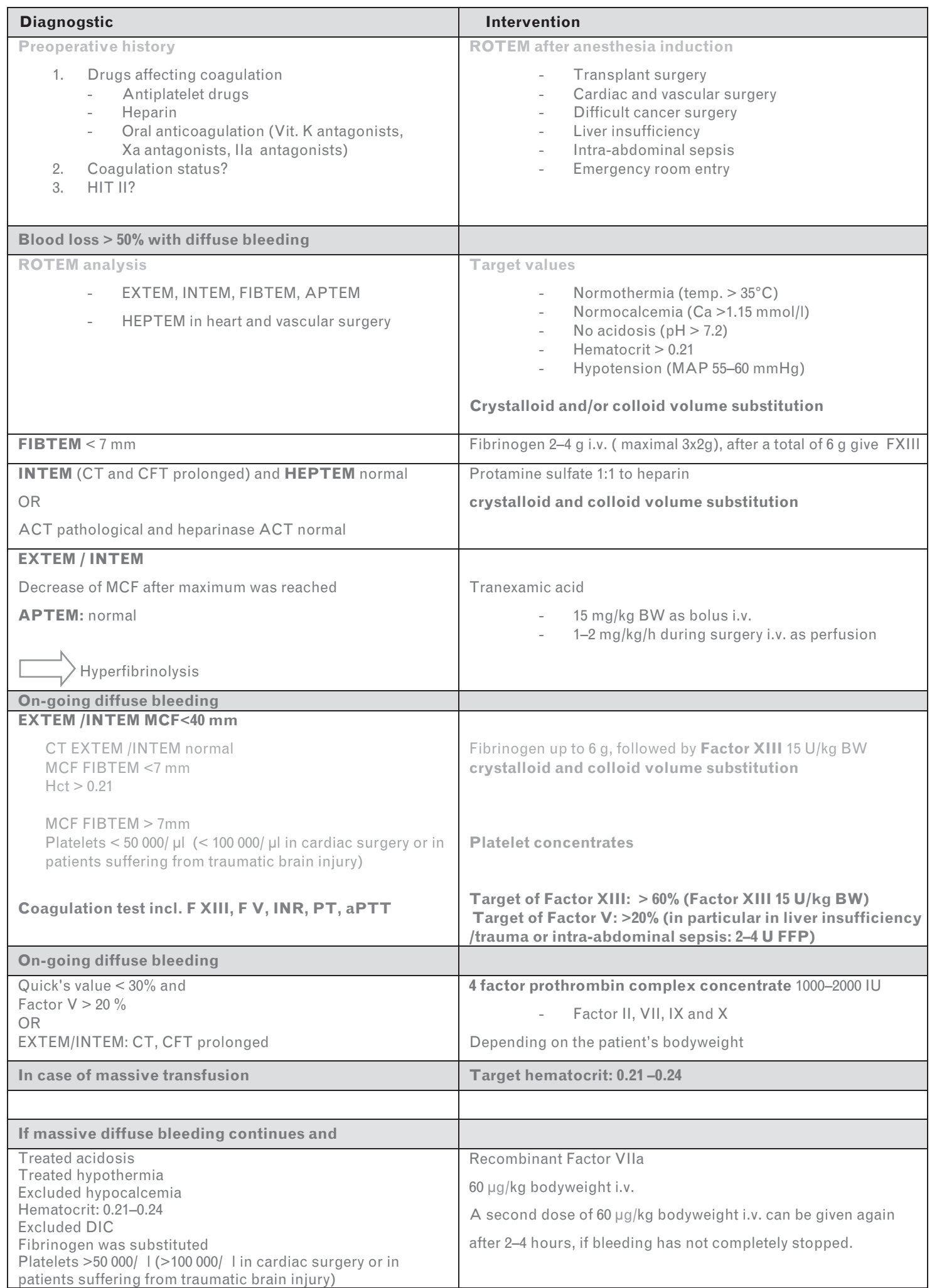

FIGURE 1. Third version of the transfusion algorithm of the University Hospital of Zürich 2013, Switzerland. BW, body weight; CFT, clot formation time; FFP, fresh frozen plasma; HIT, heparin-induced thrombocytopenia; INR, international normalized ratio; i.v., intravenous; MAP, mean arterial pressure; MCF, maximal clot firmness. Adapted with permission [77"']. 
doses to prevent thromboembolic adverse events [1"',92].

In addition to all factor concentrates, one should take the two following drugs into consideration: first, tranexamic acid (TXA), which stops hyperfibrinolysis, reduces the need for blood products and decreases mortality [94] and second, desmopressin, which enhances platelet adherence [94-99]. There is actually clear evidence that the early use of TXA is favorable for patients. One study, including 40 trauma patients $(55 \%$ penetrating, $45 \%$ blunt trauma), all received TXA in the prehospital setting showing that this is feasible without delaying treatment or creating severe adverse events [100"']. However, patients' outcome could not be assessed because of the study design and the limited sample size. The most known study, named CRASH-2, showed that early (within first $3 \mathrm{~h}$ ) administration of TXA in the emergency room reduces mortality significantly [94]. Furthermore, TXA is cost effective and has been integrated into military trauma algorithms [101"']. A recent systematic Cochrane review showed that TXA clearly reduces blood transfusions in patients requiring emergency or urgent surgery [102"].

Regarding desmopressin, the European Trauma Guidelines recommend a single dose for trauma patients treated with aspirin [1"'].

\section{TRANSFUSION AND PATIENT OUTCOME}

Today, in many countries, the widespread approach is to transfuse bleeding trauma patients with FFP and RBCs at a $1: 1$ ratio. Halmin et al. [103] recently published a cohort study on the association between death in trauma and FFP:RBC ratio integrating time-dependent data, as suggested by Ho et al. [104]. In their retrospective cohort study including nearly 750 patients from one single trauma center, they analyzed time-dependent transfusions and the relative risk of death comparing low and high FFP : RBC ratios. They could find no significant association between the low plasma ratio and the risk of death. On the other side, when analyses were made excluding the time factor, a strong effect of high plasma ratios was seen, clearly pointing out a survival bias [103]. This high FFP: RBC regimen is supported by observational studies mainly from recent wars, showing lower mortality in bleeding patients receiving equal volumes of plasma and RBCs as compared with patients treated with a lower FFP : RBC ratio. The rationale for this practice is still unclear with several studies failing to show any survival benefits of increased plasma use, perhaps because of a failure to account for the timing of transfused units. The FFP : RBC ratio measured $24 \mathrm{~h}$ after admission was based primarily on war casualties, in which it was realized that RBCs alone have no effect on coagulation but the addition of FFP ameliorates coagulation.

The observation of a higher survival rate in patients having received an equivalent number of FFP and RBC transfusion at $24 \mathrm{~h}$ after admission, however, suffers from this 'survival bias'. Several studies have addressed this issue. Ho et al. $[104,105]$ were able to show that there is a timedependent covariate regarding high FFP : RBC ratios and so far, the current available evidence is inconclusive. Any retrospective analysis favors patients having received high FFP:RBC ratio because only they survived long enough to receive high amounts of FFP. Those dying early did not survive long enough to have FFPs being ready to be administered $\left[106,107^{-"}\right]$. This dilemma can only be solved with prospective randomized studies. Nascimento et al. [107"'] indeed published in 2013 such a prospective randomized controlled study with 78 patients assessing the feasibility of such a study and the effect on mortality and complications in severe trauma patients. Patients were randomly assigned to a fixed ratio of $1: 1: 1$ transfusion (1 unit of RBC, FFP and platelets) $(n=40)$ or to a laboratory guided transfusion protocol which served as the control group $(n=38)$ [107"']. The all-cause 28 -day mortality was $32 \%$ in the fixed-ratio group compared to $14 \%$ in the control group and thus increased by a relative risk of 2.27 (95\% CI 0.98-9.63). Event-free survival was $54 \%$ in the patients with fixed ratios compared to $78 \%$ in the control group $(P=0.053)$. The fixed-ratio transfusion protocol was feasible but associated with large plasma wastage and a near significantly higher mortality [107"'].

There is a great need for further studies on this subject to clearly identify the optimal treatment of massively bleeding trauma patients. Furthermore, it has recently been shown that there is a clear causation between blood transfusions and bad outcome, this may also be true in trauma patients and thus one should consider giving as little blood as possible and as much as necessary in order to have a better outcome [108]. This can be guided by a clear algorithm that has to be followed by the whole staff in charge. Theusinger et al. [77"'] recently published a good example for a feasible algorithm.

\section{CONCLUSION}

Transfusion in trauma has to be an individual decision for a specific patient, not for a specific laboratory value. Transfusion management must aim on reducing or even avoiding the use of allogeneic blood products. This may lead to a new gold 
standard with cost reduction and amelioration of outcome of major trauma patients.

\section{Acknowledgements}

None.

\section{Conflicts of interest}

Oliver M. Theusinger has received honoraria or travel support for consulting or lecturing from the following companies: CSL Behring Schweiz, Zurich, Switzerland; Vifor SA, Villars-sur-Glâne, Switzerland; Roche Pharma (Schweiz) AG, Reinach, Switzerland; Pentapharm AG, München, Germany; TEM International, München, Germany.

Philipp Stein has no conflict of interest.

Donat $R$. Spahn academic department is receiving grant support from the Swiss National Science Foundation, Berne, Switzerland (grant numbers: 33CM30_124117 and 406440-131268); the Swiss Society of Anesthesiology and Reanimation (SGAR), Berne, Switzerland (no grant numbers are attributed); the Swiss Foundation for Anesthesia Research, Zurich, Switzerland (no grant numbers are attributed); Bundesprogramm Chancengleichheit, Berne, Switzerland (no grant numbers are attributed); CSL Behring, Berne, Switzerland (no grant numbers are attributed); Vifor SA, Villars-sur-Glâne, Switzerland (no grant numbers are attributed).

Dr Spahn was the chairman of the ABC Faculty and a member of the $A B C$ Trauma Faculty both of which are managed by Thomson Physicians World GmbH, Mannheim, Germany and sponsored by an unrestricted educational grant from Novo Nordisk $A / S$, Bagsvärd, Denmark. In the past 5 years, Dr Spahn has received honoraria or travel support for consulting or lecturing from the following companies: Abbott AG, Baar, Switzerland; AstraZeneca AG, Zug, Switzerland; Bayer (Schweiz) AG, Zürich, Switzerland; Baxter S.p.A., Roma, Italy; B. Braun Melsungen AG, Melsungen, Germany; Boehringer Ingelheim (Schweiz) GmbH, Basel, Switzerland; Bristol-Myers Squibb, Rueil-Malmaison Cedex, France; CSL Behring GmbH, Hattersheim am Main, Germany and Bern, Switzerland; Curacyte AG, Munich, Germany; Ethicon Biosurgery, Sommerville, New Jersey, USA; Fresenius SE, Bad Homburg v.d.H., Germany; Galenica AG, Bern, Switzerland (including Vifor SA, Villars-sur-Glâne, Switzerland); GlaxoSmithKline GmbH \& Co. KG, Hamburg, Germany; Janssen-Cilag $A G$, Baar, Switzerland; Novo Nordisk A/S, Bagsvärd, Denmark; Octapharma AG, Lachen, Switzerland; Organon AG, Pfäffikon/SZ, Switzerland; Oxygen Biotherapeutics, Costa Mesa, California, USA; Pentapharm $\mathrm{GmbH}$ (now Tem Innovations GmbH), Munich, Germany; Roche Pharma (Schweiz) AG, Reinach, Switzerland and Schering-Plough International, Inc., Kenilworth, New Jersey, USA.

\section{REFERENCES AND RECOMMENDED READING}

Papers of particular interest, published within the annual period of review, have been highlighted as:

- of special interest

- - of outstanding interest

1. Spahn DR, Bouillon B, Cerny V, et al. Management of bleeding and - coagulopathy following major trauma: an updated European guideline. Crit Care 2013; 17:R76.

This study is the updated version of the European Trauma guideline published in 2007 and updated in 2010. Key changes include new recommendations on the appropriate use of vasopressors and inotropic agents and reflect an awareness of the growing number of patients in the population at large treated with antiplatelet agents and/or oral anticoagulants. A significant addition is a new section that discusses the need for every institution to develop, implement and adhere to an evidence-based clinical protocol to manage traumatically injured patients. The remaining recommendations have been reevaluated and graded based on literature published since the last edition of the guideline. Consideration was also given to changes in clinical practice that have taken place during this time period as a result of both new evidence and changes in the general availability of relevant agents and technologies.

2. Cothren CC, Moore EE, Hedegaard HB, Meng K. Epidemiology of urban trauma deaths: a comprehensive reassessment 10 years later. World J Surg 2007; 31:1507-1511.

3. Champion HR, Bellamy RF, Roberts CP, Leppaniemi A. A profile of combat injury. J Trauma 2003; 54:S13-S19.

4. Rossaint R, Bouillon $B$, Cerny V, et al. The STOP the Bleeding Campaign. - Crit Care 2013; 17:136.

This study deals with the fact that traumatic injuries worldwide are responsible for over 5 million deaths annually. Bleeding caused by traumatic injury-associated coagulopathy is the leading cause of potentially preventable death among trauma patients. Despite these facts, awareness of this problem is insufficient and treatment options are often unclear. The STOP the Bleeding Campaign, therefore, aims to increase awareness of this fact and its appropriate management by publishing European guidelines for the management of the bleeding trauma patient, by promoting and monitoring the implementation of these guidelines and by preparing promotional and educational material, organizing activities and developing health quality management tools. The campaign aims to reduce the number of patients who die within $24 \mathrm{~h}$ after arrival in the hospital due to exsanguination by a minimum of $20 \%$ within the next 5 years.

5. Esposito TJ, Sanddal TL, Reynolds SA, Sanddal ND. Effect of a voluntary trauma system on preventable death and inappropriate care in a rural state. J Trauma 2003; 54:663-669.

6. Kauvar DS, Lefering R, Wade CE. Impact of hemorrhage on trauma outcome: an overview of epidemiology, clinical presentations, and therapeutic considerations. J Trauma 2006; 60:S3-11.

7. British Committee for Standards in Haematology. Retter A, Wyncoll D, Pearse $\mathrm{R}$, et al. Guidelines on the management of anaemia and red cell transfusion in adult critically ill patients. Br J Haematol 2013; 160:445464.

8. Clinical Transfusion Medicine Committee of the AABB. Carson JL, Grossman $\mathrm{BJ}$, Kleinman S, et al. Red blood cell transfusion: a clinical practice guideline from the AABB*. Ann Intern Med 2012; 157:49-58.

9. Carson JL, Carless PA, Hebert PC. Transfusion thresholds and other strategies for guiding allogeneic red blood cell transfusion. Cochrane Database Syst Rev 2012; 4:CD002042.

10. Frith D, Goslings JC, Gaarder C, et al. Definition and drivers of acute traumatic coagulopathy: clinical and experimental investigations. J Thromb Haemost 2010; 8:1919-1925.

11. Frith $D$, Brohi $K$. The acute coagulopathy of trauma shock: clinical relevance. Surgeon 2010; 8:159-163.

12. Spahn DR, Goodnough LT. Alternatives to blood transfusion. Lancet 2013; - 381:1855-1865.

This study summarizes the current roles of alternatives to blood in the management of medical and surgical anemias.

13. Spahn DR, Shander A, Hofmann A. The chiasm: transfusion practice versus

- patient blood management. Best Pract Res Clin Anaesthesiol 2013; 27:3742.

This publication encourages the implementation of patient blood management.

14. Shander A, Hofmann A, Isbister J, Van Aken H. Patient blood management: -1. the new frontier. Best Pract Res Clin Anaesthesiol 2013; 27:5-10.

Blood transfusions face many issues, including questionable safety and efficacy, increasing costs and limited supply. The need to provide effective care for a relatively small population of patients who could not be transfused for various reasons gave rise to 'bloodless medicine and surgery', which was subsequently proposed as a care strategy for all patients, with the goal of minimizing the use of allogeneic blood components. The next evolution came from the shift from a 'product-centered' approach toward a 'patient-centered' approach, that is, a focus on patient outcome rather than use of blood components, which gave birth to 'patient blood management'. 
15. College of American Pathologists, American Society of Anesthesiologists, Society of Thoracic Surgeons and Society of Cardiovascular Anesthesiologists, Society of Critical Care Medicine, Italian Society of Transfusion Medicine and Immunohaematology, American Association of Blood Banks. Shander A, Gross I, Hill S, et al. A new perspective on best transfusion practices. Blood Transfus 2013; 11:193-202.

16. Williamson LM, Devine DV. Challenges in the management of the blood -. supply. Lancet 2013; 381:1866-1875.

In the the next 5-10 years, blood availability in developed countries will need to increase again to meet the demands of aging populations. Increasing of the blood supply raises many challenges; new approaches to recruitment and retainment of future generations of blood donors will be needed, and care will be necessary to avoid taking too much blood from these donors. Personalized medicine could be applied to match donors to patients, not only with extended blood typing, but also by using genetically determined storage characteristics of blood components. Growing of red cells or platelets in large quantities from stem cells is a possibility in the future, but challenges of cost, scaling up and reproducibility remain to be solved.

17. Ives $\mathrm{C}$, Inaba K, Branco BC, et al. Hyperfibrinolysis elicited via thromboelastography predicts mortality in trauma. J Am Coll Surg 2012; 215:496502.

18. Johansson PI, Stensballe J, Ostrowski SR. Current management of massive hemorrhage in trauma. Scand J Trauma Resusc Emerg Med 2012; 20:47.

19. Strobel E. Hemolytic transfusion reactions. Transfus Med Hemother 2008; 35:346-353.

20. Kenz HE, Van der Linden P. Transfusion-related acute lung injury. Eur J

- Anaesthesiol 2014; 31:345-350.

This article describes transfusion-related lung injury, its occurrence, its supposed pathomechanism and possible treatment algorithms.

21. Rana R, Fernandez-Perez ER, Khan SA, et al. Transfusion-related acute lung injury and pulmonary edema in critically ill patients: a retrospective study. Transfusion 2006; 46:1478-1483

22. Vlaar AP, Juffermans NP. Transfusion-related acute lung injury: a clinical

- review. Lancet 2013; 382:984-994.

This article describes transfusion-related lung injury, its occurrence, its supposed pathomechanism and possible treatment algorithms.

23. Prestia K, Bandyopadhyay S, Slate A, et al. Transfusion of stored blood

- impairs host defenses against Gram-negative pathogens in mice. Transfusion 2014. [Epub ahead of print]

This original article enlightens the adverse host reactions after transfusion of stored or older blood in mice. Consecutively lowered defense host mechanisms against bacteria are also considered to be of relevance in the human body, this work reveals possible mechanisms.

24. Spahn DR. Anemia and patient blood management in hip and knee surgery: a systematic review of the literature. Anesthesiology 2010; 113:482495

25. Bernard AC, Davenport DL, Chang PK, et al. Intraoperative transfusion of $1 \mathrm{U}$ to $2 \mathrm{U}$ packed red blood cells is associated with increased 30-day mortality, surgical-site infection, pneumonia, and sepsis in general surgery patients. J Am Coll Surg 2009; 208:931-937.

26. Weinberg JA, McGwin G Jr, Marques MB, et al. Transfusions in the less severely injured: does age of transfused blood affect outcomes? J Trauma 2008; 65:794-798.

27. Vandromme MJ, McGwin G Jr, Marques MB, et al. Transfusion and pneumonia in the trauma intensive care unit: an examination of the temporal relationship. J Trauma 2009; 67:97-101.

28. Juffermans NP, Vlaar AP, Prins DJ, et al. The age of red blood cells is associated with bacterial infections in critically ill trauma patients. Blood transfusion 2012; 10:290-295

29. Keller ME, Jean R, LaMorte WW, et al. Effects of age of transfused blood on length of stay in trauma patients: a preliminary report. J Trauma 2002; 53:1023-1025

30. Murrell Z, Haukoos JS, Putnam B, Klein SR. The effect of older blood on mortality, need for ICU care, and the length of ICU stay after major trauma. Am Surg 2005; 71:781-785

31. Spinella PC, Carroll CL, Staff I, et al. Duration of red blood cell storage is associated with increased incidence of deep vein thrombosis and in hospital mortality in patients with traumatic injuries. Crit Care 2009; 13:R151.

32. Zallen G, Offner PJ, Moore EE, et al. Age of transfused blood is an independent risk factor for postinjury multiple organ failure. Am J Surg 1999; 178:570-572

33. Weinberg JA, McGwin G Jr, Vandromme MJ, et al. Duration of red cell storage influences mortality after trauma. J Trauma 2010; 69:1427-1431.

34. Snyder HS. Significance of the initial spun hematocrit in trauma patients. Am J Emerg Med 1998; 16:150-153.

35. Zehtabchi S, Sinert R, Goldman M, et al. Diagnostic performance of serial haematocrit measurements in identifying major injury in adult trauma patients. Injury 2006; 37:46-52.

36. Ryan ML, Thorson CM, Otero CA, et al. Initial hematocrit in trauma: a paradigm shift? J Trauma Acute Care Surg 2012; 72:54-59.

37. Thorson CM, Ryan ML, Van Haren RM, et al. Change in hematocrit during trauma assessment predicts bleeding even with ongoing fluid resuscitation. Am Surg 2013; 79:398-406
38. Kinoshita Y, Yamane T, Takubo T, et al. Measurement of hemoglobin concentrations using the astrim noninvasive blood vessel monitoring apparatus. Acta Haematol 2002; 108:109-110.

39. Berkow L, Rotolo S, Mirski E. Continuous noninvasive hemoglobin monitoring during complex spine surgery. Anesth Analg 2011; 113:1396-1402.

40. Nguyen BV, Vincent JL, Nowak $\mathrm{E}$, et al. The accuracy of noninvasive hemoglobin measurement by multiwavelength pulse oximetry after cardiac surgery. Anesth Analg 2011; 113:1052-1057.

41. Joseph B, Hadjizacharia P, Aziz H, et al. Continuous noninvasive hemoglobin

- monitor from pulse ox: ready for prime time? World J Surg 2013; 37:525529

This article deals with noninvasive hemoglobin measurement in trauma patients and reveals the lack of sufficient current accuracy in severly injured patients.

42. Moore $L$, Wade $C E$, Vincent $L$, et al. Evaluation of noninvasive hemoglobin measurements in trauma patients. Am J Surg 2013; 206:1041-1047.

43. Seldon TH, Lundy JS, Adams RC. A blood transfusion service; dangers and safeguards. Anesthesiology 1946; 7:122-131.

44. Wu WC, Schifftner TL, Henderson WG, et al. Preoperative hematocrit levels and postoperative outcomes in older patients undergoing noncardiac surgery. JAMA 2007; 297:2481-2488

45. Musallam KM, Tamim HM, Richards T, et al. Preoperative anaemia and postoperative outcomes in noncardiac surgery: a retrospective cohort study. Lancet 2011; 378:1396-1407.

46. Pattakos G, Koch CG, Brizzio ME, et al. Outcome of patients who refuse transfusion after cardiac surgery: a natural experiment with severe blood conservation. Arch Intern Med 2012; 172:1154-1160.

47. Chaiwat O, Lang JD, Vavilala MS, et al. Early packed red blood cell transfusion and acute respiratory distress syndrome after trauma. Anesthesiology 2009; 110:351-360

48. Madjdpour C, Spahn DR, Weiskopf RB. Anemia and perioperative red blood cell transfusion: a matter of tolerance. Crit Care Med 2006; 34:S102-S108.

49. Villanueva $C$, Colomo A, Bosch A. Transfusion for acute upper gastrointest-I inal bleeding. N Engl J Med 2013; 368:1362-1363.

A large randomized controlled trial comparing liberal with restrictive transfusion triggers. Restrictive transfusion strategy improves outcomes in patiens with acute upper gastrointestinal bleeding.

50. Carson JL, Terrin ML, Noveck H, et al. Liberal or restrictive transfusion in highrisk patients after hip surgery. N Engl J Med 2011; 365:2453-2462.

51. Mclntyre $L$, Hebert $P C$, Wells $G$, et al. Is a restrictive transfusion strategy safe for resuscitated and critically ill trauma patients? J Trauma 2004; 57:563568

52. Smith MJ, Stiefel MF, Magge S, et al. Packed red blood cell transfusion increases local cerebral oxygenation. Crit Care Med 2005; 33:1104-1108.

53. Leal-Noval SR, Munoz-Gomez M, Arellano-Orden V, et al. Impact of age of transfused blood on cerebral oxygenation in male patients with severe traumatic brain injury. Crit Care Med 2008; 36:1290-1296.

54. Zygun DA, Nortje J, Hutchinson PJ, et al. The effect of red blood cell transfusion on cerebral oxygenation and metabolism after severe traumatic brain injury. Crit Care Med 2009; 37:1074-1078.

55. Carlson AP, Schermer CR, Lu SW. Retrospective evaluation of anemia and transfusion in traumatic brain injury. J Trauma 2006; 61:567-571.

56. Salim A, Hadjizacharia $P$, DuBose $\mathrm{J}$, et al. Role of anemia in traumatic brain injury. J Am Coll Surg 2008; 207:398-406.

57. Fluckiger C, Bechir M, Brenni M, et al. Increasing hematocrit above $28 \%$ during early resuscitative phase is not associated with decreased mortality following severe traumatic brain injury. Acta Neurochir 2010; 152:627636

58. Yang CJ, Hsiao KY, Su IC, Chen IC. The association between anemia and the mortality of severe traumatic brain injury in emergency department. J Trauma 2011; 71:E132-E135.

59. Sisak K, Manolis M, Hardy BM, et al. Acute transfusion practice during trauma - resuscitation: who, when, where and why? Injury 2013; 44:581-586.

In this publication, distinct patterns of early transfusion triggers are revealed to guide transfusion indications in contrast to conventional hemoglobin values as transfusion triggers.

60. Callcut RA, Cotton BA, Muskat $P$, et al. Defining when to initiate massive

- transfusion: a validation study of individual massive transfusion triggers in PROMMTT patients. J Trauma Acute Care Surg 2013; 74:59-65.

A large trial comprising 1245 trauma patients of which 237 had a massive transfusion. Individual clinical triggers for transfusion such as INR and positive results for focused assessment with sonography for trauma were identified to predict the likelihood of massive transfusion.

61. Maegele M, Brockamp T, Nienaber U, et al. Predictive models and algorithms for the need of transfusion including massive transfusion in severely injured patients. Transfus Med Hemother 2012; 39:85-97.

62. Zollinger $A$, Hager $P$, Singer $T$, et al. Extreme hemodilution due to massive blood loss in tumor surgery. Anesthesiology 1997; 87:985-987.

63. Dai J, Tu W, Yang Z, Lin R. Case report: intraoperative management of extreme hemodilution in a patient with a severed axillary artery. Anesth Analg 2010; 111:1204-1206

64. de Araujo Azi LM, Lopes FM, Garcia LV. Postoperative management of severe acute anemia in a Jehovah's Witness. Transfusion 2014; 54:11531157. 
65. Hare GM. Tolerance of anemia: understanding the adaptive physiological - mechanisms which promote survival. Transfus Apher Sci 2014; 50:10-12. Physiological compensation mechanisms play a vital role to overcome acute severe anemia. Cardiovascular and cellular responses are key to maintaining survival. Molecular mechanisms, such as neuronal nitric oxide synthase and hypoxia-inducible factor, may promote survival. Oxidation of hemoglobin to methemoglobin by nitric oxide synthase may be a marker of anemia-induced tissue hypoxia.

66. Klein HG, Spahn DR, Carson JL. Red blood cell transfusion in clinical practice. Lancet 2007; 370:415-426.

67. Meier J, Kemming GI, Kisch-Wedel H, et al. Hyperoxic ventilation reduces 6-h mortality at the critical hemoglobin concentration. Anesthesiology 2004; 100:70-76.

68. Pape $A$, Steche $M$, Laout $M$, et al. The limit of anemia tolerance during

- hyperoxic ventilation with pure oxygen in anesthetized domestic pigs. Eur Surg Res 2013; 51:156-169.

This animal study reveals the body limits of whole body hypoxic anemia, also in the context of variable inspiratory fractions of oxygen.

69. Lauscher $\mathrm{P}$, Kertscho $\mathrm{H}$, Schmidt $\mathrm{O}$, et al. Determination of organ-specific nemia tolerance. Crit Care Med 2013; 41:1037-1045.

In this trial, pigs were randomized into three different groups and hemodiluted with hydroxyethyl starch comparing no hemodilution vs. hemoglobin of $4.0 \mathrm{~g} / \mathrm{dl}$ and vs. the critical hemoglobin level of $2.7 \mathrm{~g} / \mathrm{dl}$. In the hemodiluted state, $10 \mathrm{mg} / \mathrm{kg}$ of pimonidazole was injected, which forms protein adducts in hypoxic cells. Interestingly, metabolic parameters and oxygen consumption did not show that tissue oxygenation was restricted before reaching a hemoglobin level of $2.7 \mathrm{~g} / \mathrm{dl}$. Kidneys and skeletal muscle showed enhanced pimonidazole binding and vascular endothelial growth factor expression at a hemoglobin level of $4 \mathrm{~g} / \mathrm{dl}$. Other organs such as heart, brain and liver showed no signs of tissue hypoxia at a hemoglobin level of $4 \mathrm{~g} / \mathrm{dl}$

70. Pape A, Kertscho H, Stein P, et al. Neuromuscular blockade with rocuronium bromide increases the tolerance of acute normovolemic anemia in anesthetized pigs. Eur Surg Res 2012; 48:16-25.

71. McCullough JN, Zhang N, Reich DL, et al. Cerebral metabolic suppression during hypothermic circulatory arrest in humans. Ann Thorac Surg 1999; 67:1895-1899.

72. Meier J, Pape A, Loniewska D, et al. Norepinephrine increases tolerance to acute anemia. Crit Care Med 2007; 35:1484-1492.

73. Nienaber $U$, Innerhofer $P$, Westermann I, et al. The impact of fresh frozen plasma vs coagulation factor concentrates on morbidity and mortality in trauma-associated haemorrhage and massive transfusion. Injury 2011; 42:697-701

74. Trauma Registry of the Deutsche Gesellschaft fur Unfallchirurgie. Peiniger S, Nienaber U, Lefering R, et al. Balanced massive transfusion ratios in multiple injury patients with traumatic brain injury. Crit Care 2011; 15:; R68.

75. Pape H-C, Neugebauer E, Ridley SA, et al. Cost-drivers in acute treatment of severe trauma in europe: a systematic review of literature. Eur J Trauma Emerg Surg 2009; 35:61-66.

76. Walsh TS. Red cell transfusion triggers in critically ill patients: time for some new TRICCs? Crit Care 2010; 14:170.

77. Theusinger OM, Stein $P$, Spahn DR. Applying 'patient blood management' in .1. the trauma center. Curr Opin Anaesthesiol 2014; 27:225-232.

This review highlights the use of TXA, POC testing, algorithm-based treatment of trauma-associated coagulopathy with factor concentrates to reduce blood loss and transfusion requirements to improve outcome. In addition, the management of patients on new oral anticoagulants, drugs with renewed interest and the tolerance of relatively low hemoglobin levels in the context of trauma is discussed.

78. Theusinger OM, Schroder $\mathrm{CM}$, Eismon J, et al. The influence of laboratory

- coagulation tests and clotting factor levels on Rotation Thromboelastometry (ROTEM(R)) during major surgery with hemorrhage. Anesth Analg 2013; 117:314-321.

This study confirms the clinical assumption that EXTEM, INTEM and APTEM are associated with fibrinogen and platelets levels; INTEM-CT significantly to aPTT and FIBTEM significantly to fibrinogen. Factor VIII shows a significant correlation with all ROTEM parameters except CT of EXTEM, INTEM, FIBTEM, and clot formation time and maximal clot firmness of APTEM.

79. Theusinger OM, Levy JH. Point of care devices for assessing bleeding

-1. and coagulation in the trauma patient. Anesthesiol Clin 2013; 31:5565.

Severe trauma is associated with bleeding, coagulopathy, and transfusion of blood and blood products, all contributing to higher rates of morbidity and mortality. This review focuses on POC devices to monitor coagulation in trauma. Close monitoring of bleeding and coagulation as well as platelet function in trauma patients allows goal-directed transfusion and an optimization of the patient's coagulation, reduces the exposure to blood products, reduces costs, and probably improves clinical outcome. Noninvasive hemoglobin measurements are not to be used in trauma patients because of a lack in specificity and sensitivity.

80. Theusinger OM, Nurnberg J, Asmis LM, et al. Rotation thromboelastometry (ROTEM) stability and reproducibility over time. Eur J Cardiothorac Surg 2010; 37:677-683.

81. Ganter MT, Hofer CK. Coagulation monitoring: current techniques and clinical use of viscoelastic point-of-care coagulation devices. Anesth Analg 2008; 106:1366-1375
82. Mahambrey $T$, Pendry $K$, Nee A, et al. Critical care in emergency department: - massive haemorrhage in trauma. Emerg Med J 2013; 30:9-14.

This article addresses current concepts in hemostatic resuscitation. Recent guidelines on the diagnosis and treatment of coagulopathy in major trauma, and the role of component and adjuvant therapies, are considered. Finally, the potential role of thromboelastography and rotational thromboelastometry are discussed.

83. Kozek-Langenecker S, Sorensen B, Hess JR, Spahn DR. Clinical effectiveness of fresh frozen plasma compared with fibrinogen concentrate: a systematic review. Crit Care 2011; 15:R239.

84. Schochl H, Nienaber $U$, Maegele $M$, et al. Transfusion in trauma: thromboelastometry-guided coagulation factor concentrate-based therapy versus standard fresh frozen plasma-based therapy. Crit Care 2011; 15:R83.

85. Theusinger OM, Baulig W, Seifert B, et al. Relative concentrations of haemostatic factors and cytokines in solvent/detergent-treated and freshfrozen plasma. Br J Anaesth 2011; 106:505-511.

86. Theusinger OM. The inhibiting effect of factor XIII on hyperfibrinolysis. Anesth Analg 2012; 114:1149-1150.

87. Theusinger OM, Spahn DR, Ganter MT. Transfusion in trauma: why and how should we change our current practice? Curr Opin Anaesthesiol 2009; 22:305-312

88. Dirkmann D, Gorlinger K, Gisbertz C, et al. Factor XIII and tranexamic acid but not recombinant factor VIla attenuate tissue plasminogen activator-induced hyperfibrinolysis in human whole blood. Anesth Analg 2012; 114:11821188.

89. Gorlinger K, Dirkmann D, Hanke AA, et al. First-line therapy with coagulation factor concentrates combined with point-of-care coagulation testing is associated with decreased allogeneic blood transfusion in cardiovascular surgery: a retrospective, single-center cohort study. Anesthesiology 2011; 115:1179-1191.

90. Theusinger OM, Felix C, Spahn DR. Strategies to reduce the use of blood products: a European perspective. Curr Opin Anaesthesiol 2012; 25:5965.

91. Theusinger OM, Madjdpour C, Spahn DR. Resuscitation and transfusion management in trauma patients: emerging concepts. Curr Opin Crit Care 2012; 18:661-670.

92. Sorensen B, Spahn DR, Innerhofer $P$, et al. Clinical review: prothrombin complex concentrates: evaluation of safety and thrombogenicity. Crit Care $2011 ; 15: 201$.

93. Schochl H, Nienaber U, Hofer G, et al. Goal-directed coagulation management of major trauma patients using thromboelastometry (ROTEM)-guided administration of fibrinogen concentrate and prothrombin complex concentrate. Crit Care 2010; 14:R55.

94. CRASH-2 collaborators. Roberts I, Shakur $\mathrm{H}$, et al. The importance of early treatment with tranexamic acid in bleeding trauma patients: an exploratory analysis of the CRASH-2 randomised controlled trial. Lancet 2011; 377:1096-1101.

95. Ruggeri ZM, Mannucci PM, Lombardi R, et al. Multimeric composition of factor VIII/von Willebrand factor following administration of DDAVP: implications for pathophysiology and therapy of von Willebrand's disease subtypes. Blood 1982; 59:1272-1278.

96. Castaman G, Goodeve A, Eikenboom J. European Group on von Willebrand D. Principles of care for the diagnosis and treatment of von Willebrand disease. Haematologica 2013; 98:667-674.

97. Beynon C, Sakowitz OW, Unterberg AW. Multiple electrode aggregometry in antiplatelet-related intracerebral haemorrhage. J Clin Neurosci 2013; 20:1805-1806.

98. CRASH-2 goes viral. Lancet $2011 ; 378: 1758$.

99. CRASH-2 trial collaborators. Shakur $\mathrm{H}$, Roberts I, et al. Effects of tranexamic acid on death, vascular occlusive events, and blood transfusion in trauma patients with significant haemorrhage (CRASH-2): a randomised, placebocontrolled trial. Lancet 2010; 376:23-32.

100. Lipsky AM, Abramovich A, Nadler R, et al. Tranexamic acid in the prehospital -1. setting: Israel Defense Forces' initial experience. Injury 2014; 45:66-70. The authors show that TXA may be successfully given in the prehospital setting without any apparent delays in evacuation. In light of recent evidence, the ability to give TXA closer to the time of wounding represents an important step toward improving the survival of trauma victims with hemorrhage, even before definitive care is available. TXA could be considered a viable option for use by advanced life support providers at or near the point of injury.

101. Roberts I, Shakur $\mathrm{H}$, Coats $\mathrm{T}$, et al. The CRASH-2 trial: a randomised

- controlled trial and economic evaluation of the effects of tranexamic acid on death, vascular occlusive events and transfusion requirement in bleeding trauma patients. Health Technol Assess 2013; 17:1-79.

This analysis shows that the early administration of TXA safely reduced the risk of death in bleeding trauma patients and is highly cost-effective. Treatment beyond $3 \mathrm{~h}$ of injury is unlikely to be effective.

102. Perel $\mathrm{P}$, Ker K, Morales Uribe $\mathrm{CH}$, Roberts I. Tranexamic acid for reducing - mortality in emergency and urgent surgery. Cochrane Database Syst Rev 2013; 1:CD010245.

The authors show by a prognostic model that one can obtain valid predictions of mortality in patients with traumatic bleeding. TXA can be administered safely to a wide spectrum of bleeding trauma patients and should not be restricted to the most severely injured. It has to be evaluated whether or not this model used in clinical practice has an impact on the management and outcomes of trauma patients. 
103. Halmin M, Bostrom F, Brattstrom $O$, et al. Effect of plasma-to-RBC ratios in trauma patients: a cohort study with time-dependent data*. Crit Care Med 2013; 41:1905-1914.

104. Ho AM, Dion PW, Yeung JH, et al. Prevalence of survivor bias in observational studies on fresh frozen plasma:erythrocyte ratios in trauma requiring massive transfusion. Anesthesiology 2012; 116:716728.

105. Ho AM, Dion PW, Yeung $\mathrm{JH}$, et al. Simulation of survivorship bias in observational studies on plasma to red blood cell ratios in massive transfusion for trauma. Br J Surg 2012; 99 (Suppl 1):132-139.
106. Brown LM, Aro SO, Cohen MJ, et al. A high fresh frozen plasma: packed red blood cell transfusion ratio decreases mortality in all massively transfused trauma patients regardless of admission international normalized ratio. J Trauma 2011; 71:S358-S363.

107. Nascimento $B, C$ allum J, Tien $H$, et al. Effect of a fixed-ratio $(1: 1: 1)$ transfusion

- protocol versus laboratory-results-guided transfusion in patients with severe trauma: a randomized feasibility trial. CMAJ 2013; 185:E583-E589.

This article shows a near significant higher mortality in the fixed ratio $(1: 1: 1 \mathrm{PRB}$,

FFP, platelets) transfusion group compared to a laboratory guided protocol.

108. Isbister JP, Shander A, Spahn DR, et al. Adverse blood transfusion outcomes: establishing causation. Transfus Med Rev 2011; 25:89-101. 